\title{
The J loop of the spatial vectorcardiogram in accidental hypothermia in man
}

\author{
D. Maclean and D. Emslie-Smith \\ From the Department of Medicine, Ninewells Hospital and Medical School, Dundee.
}

The $\mathcal{F}$ loop of the spatial vectorcardiogram has been studied, using the Frank system of lead placement, in 25 patients with accidental hypothermia. There was a highly significant correlation $(P<0.0025)$ between the duration of the 7 loop (range 40-160 msec) and the severity of the hypothermia, but its rate of inscription may (a) be uniform throughout, (b) slow progressively throughout, or (c) slow only towards its end. The variation in the form of the $\mathcal{f}$ deflections in scalar electrocardiographic leads during hypothermia is determined by the spatial interrelation of the axes of these leads and the $\mathcal{F}$ loop of the spatial vectorcardiogram. An appreciation of this relation emphasizes the true nature and significance of the less well-known forms of the scalar $\mathcal{F}$ deflections in hypothermia. These findings may be determined by changes induced by hypothermia in the permeability of the myocardial cell membranes and ionic fluxes across them. Despite severe hypothermia, one patient had no scalar $\mathcal{F}$ deflection and no $\mathcal{F}$ loop was present in the corresponding spatial vectorcardiogram.

In 1938, Tomaszewski first published the scalar electrocardiogram of a patient with accidental hypothermia which showed the extra deflection that was later to be termed the ' $\mathrm{J}$ deflection' (EmslieSmith, 1958a; Emslie-Smith, Sladden, and Stirling, 1959). It forms a conspicuous and rather puzzling feature of the scalar electrocardiogram of hypothermia either induced (Emslie-Smith, 1956; Fleming and Muir, 1957; Emslie-Smith et al., 1959) or accidental (Emslie-Smith, 1957, 1958a; Rees, 1958). It has also been recorded experimentally from various species of hypothermic mammals (Grosse-Brockhoff and Schoedel, 1943).

The $J$ loop of the spatial vectorcardiogram is the vectorial homologue of the scalar J deflection. Apart from experimental three-plane electronically synthesized spatial vectorcardiograms recorded from a single dog during cooling (Emslie-Smith, I958b), the only studies of the spatial $J$ loop were made on indirectly constructed vectorcardiograms from patients with induced hypothermia (Emslie-Smith, 1958b; Gillmann, 1958) and no previous study has been made of the directly recorded, electronically synthesized spatial vectorcardiogram in patients with accidental hypothermia (Fig. Ia and b).

Since accidental hypothermia was first described as a common condition in British homes in winter (Emslie-Smith, 1958a), it has become widely

Received 6 February 1974. accepted as a serious cause of mortality in the elderly (Royal College of Physicians, I966). In I967 we therefore started this study of the J loop of the spatial vectorcardiogram in patients with accidental hypothermia and we now report the results.

\section{Methods and clinical data}

Twenty-five of the patients with accidental hypothermia admitted to the Dundee teaching hospitals over a period of 5 years were studied. The relevant details of the cases are shown in the Table.

In each case the vectorcardiogram in the frontal, right sagittal, and horizontal planes was recorded directly by means of either a Sanborn vectorcardiograph with storage oscilloscope and polaroid camera facilities, or a photographically recording Cambridge vectorcardiograph (No. C.538Ir) (Cameron, Lawrie, and Wright, 1959) using a modification of the Frank (1956) method of electrode placement (Maclean, Lowe, and EmslieSmith, 1970). In the first patient (Case I - Table) the vectorcardiogram was also recorded during rewarming, and in the most severely hypothermic patient (Case 20, Table: $22.8^{\circ} \mathrm{C}$ ) the vectorcardiogram was again recorded 3 months after he had completely recovered. From these planar projections the medical artist then reconstructed the spatial vectorcardiograms as threedimensional drawings. The speed of inscription of each part of the spatial vectorcardiogram was estimated from inspection of the blanking pulse which interrupted the planar loops every 5 msec. 
TABLE Clinical details and vectorcardiographic results

\begin{tabular}{|c|c|c|c|c|c|c|c|c|c|}
\hline \multirow[t]{4}{*}{$\begin{array}{l}\text { Case } \\
\text { No. }\end{array}$} & \multirow{4}{*}{$\begin{array}{l}\text { Age } \\
\text { and } \\
\text { sex }\end{array}$} & \multirow{4}{*}{$\begin{array}{l}\text { Rectal } \\
\text { temper } \\
{ }^{\circ} \mathrm{F}\end{array}$} & \multirow{4}{*}{$\begin{array}{l}\text { ure } \\
{ }^{\circ} \mathrm{C}\end{array}$} & \multicolumn{6}{|c|}{ Vectorcardiogram } \\
\hline & & & & \multicolumn{4}{|l|}{$\mathcal{F}$ vectors } & \multirow{2}{*}{\multicolumn{2}{|c|}{$\frac{T \text { loops }}{\text { Axis of max. vector }}$}} \\
\hline & & & & \multirow[t]{2}{*}{$\begin{array}{l}\text { Duration } \\
\text { (msec) }\end{array}$} & \multicolumn{2}{|c|}{$\begin{array}{l}\text { Axis of } \\
\text { initial vector }\end{array}$} & \multirow[t]{2}{*}{$\begin{array}{l}\text { Rate of } \\
\text { inscription }\end{array}$} & & \\
\hline & & & & & $F$ & $H$ & & $F$ & $H$ \\
\hline $\mathbf{r}$ & $86 \mathrm{~F}$ & $\begin{array}{l}82 \cdot 9 \\
88 \cdot 0\end{array}$ & $\begin{array}{l}28 \cdot 3 \\
3 I \cdot I\end{array}$ & $\begin{array}{r}100 \\
80\end{array}$ & $\begin{array}{l}28^{\circ} \\
45^{\circ}\end{array}$ & $\begin{array}{l}27^{\circ} \\
30^{\circ}\end{array}$ & Progressive decrease & $145^{\circ}$ & $82^{\circ}$ \\
\hline 2 & $23 \mathrm{M}$ & $86 \cdot 0$ & $30 \cdot 0$ & 45 & $45^{\circ}$ & $0^{\circ}$ & Terminal slowing only & $47^{\circ}$ & $35^{\circ}$ \\
\hline 3 & $42 \mathrm{~F}$ & $84 \cdot 2$ & $29 \cdot 0$ & 40 & $68^{\circ}$ & $10^{\circ}$ & Terminal slowing only & $40^{\circ}$ & $33^{\circ}$ \\
\hline 4 & $35 \mathrm{~F}$ & $85 \cdot 1$ & $29 \cdot 5$ & 50 & $335^{\circ}$ & $304^{\circ}$ & Progressive decrease & $80^{\circ}$ & $58^{\circ}$ \\
\hline 5 & $86 M$ & $86 \cdot 0$ & $30 \cdot 0$ & 55 & $12^{\circ}$ & $333^{\circ}$ & Uniform & $230^{\circ}$ & $106^{\circ}$ \\
\hline 6 & $70 \mathrm{~F}$ & $93 \cdot 9$ & 34.4 & $\star$ & $\star$ & $130^{\circ}$ & Details indistinct & $90^{\circ}$ & $90^{\circ}$ \\
\hline 7 & $85 \mathrm{~F}$ & $82 \cdot 0$ & $27 \cdot 8$ & 50 & * & $0^{\circ}$ & Details indistinct & $30^{\circ}$ & $55^{\circ}$ \\
\hline 8 & $74 \mathrm{M}$ & $79 \cdot 0$ & $26 \cdot 1$ & 65 & $85^{\circ}$ & $90^{\circ}$ & Uniform & $60^{\circ}$ & $70^{\circ}$ \\
\hline 9 & $78 \mathrm{~F}$ & $85 \cdot 0$ & $29 \cdot 4$ & 45 & $13^{\circ}$ & $0^{\circ}$ & Uniform & $\star$ & $25^{\circ}$ \\
\hline I0 & $84 M$ & $88 \cdot 0$ & $3 I \cdot r$ & & $45^{\circ}$ & $55^{\circ}$ & Uniform & $65^{\circ}$ & $65^{\circ}$ \\
\hline II & $65 \mathrm{M}$ & $78 \cdot 0$ & $25 \cdot 6$ & No J loop & & & No J displacement & $85^{\circ}$ & $90^{\circ}$ \\
\hline 12 & $84 \mathrm{~F}$ & $87 \cdot 0$ & $30 \cdot 6$ & 80 & $35^{\circ}$ & $350^{\circ}$ & $\begin{array}{l}\text { Uniform for Ist } 45 \mathrm{msec} \text {; then } \\
\text { terminal slowing }\end{array}$ & $53^{\circ}$ & $45^{\circ}$ \\
\hline 13 & $77 \mathrm{~F}$ & $88 \cdot 0$ & $3 I \cdot I$ & $\star$ & $10^{\circ}$ & $45^{\circ}$ & Uniform & $110^{\circ}$ & $90^{\circ}$ \\
\hline 14 & $87 \mathrm{~F}$ & 85.0 & $29 \cdot 4$ & 60 & $\star$ & $260^{\circ}$ & Uniform & $\star$ & $50^{\circ r}$ \\
\hline I5 & $80 \mathrm{M}$ & $84 \cdot 0$ & $28 \cdot 9$ & 40 & $0^{\circ}$ & $335^{\circ}$ & Uniform & $30^{\circ}$ & $18^{\circ}$ \\
\hline I6 & $70 \mathrm{~F}$ & $89 \cdot 5$ & $3 r \cdot 9$ & 70 & $\star$ & $335^{\circ}$ & Uniform & $80^{\circ}$ & $40^{\circ}$ \\
\hline $\begin{array}{l}17 \\
18\end{array}$ & $\begin{array}{l}63 \mathrm{~F} \\
69 \mathrm{M}\end{array}$ & $\begin{array}{l}85^{\circ} 0 \\
84^{\circ} 0\end{array}$ & $\begin{array}{l}29 \cdot 4 \\
28 \cdot 9\end{array}$ & $\begin{array}{l}95 \\
60\end{array}$ & $\begin{array}{r}60^{\circ} \\
180^{\circ}\end{array}$ & $325^{\circ}$ & $\begin{array}{l}\text { Progressive decrease } \\
\text { Uniform }\end{array}$ & $\begin{array}{l}65^{\circ} \\
80^{\circ}\end{array}$ & $\begin{array}{r}100^{\circ} \\
60^{\circ}\end{array}$ \\
\hline I9 & $89 \mathrm{M}$ & $83 \cdot 0$ & $28 \cdot 3$ & 75 & $55^{\circ}$ & $335^{\circ}$ & Uniform & $90^{\circ}$ & $130^{\circ}$ \\
\hline 20 & $62 M$ & $73 \cdot 0$ & $22 \cdot 8$ & 160 & $60^{\circ}$ & $54^{\circ}$ & $\begin{array}{l}\text { Rate of inscription of } \mathrm{J} \text { loop } \\
\text { slows only in last } 80 \mathrm{msec}\end{array}$ & $180^{\circ}$ & $220^{\circ}$ \\
\hline $2 \mathbf{I}$ & $79 \mathrm{M}$ & $\begin{array}{l}98 \cdot 4 \\
85 \cdot 9\end{array}$ & $\begin{array}{l}36 \cdot 9 \\
29 \cdot 4\end{array}$ & $\begin{array}{l}\text { No J loop } \\
90\end{array}$ & * & $180^{\circ}$ & $\begin{array}{l}\text { No J displacement } \\
\text { Progressive decrease (in } \\
\text { horizontal plane) }\end{array}$ & $205^{\circ}$ & $\begin{array}{r}45^{\circ} \\
170^{\circ}\end{array}$ \\
\hline 22 & $89 \mathrm{~F}$ & $82 \cdot 0$ & $27 \cdot 8$ & 135 & $40^{\circ}$ & $55^{\circ}$ & Uniform & $215^{\circ}$ & $150^{\circ}$ \\
\hline 23 & $86 \mathrm{~F}$ & $83 \cdot 0$ & $28 \cdot 3$ & 80 & $\star$ & $330^{\circ}$ & Terminal slowing only & $\star$ & $200^{\circ}$ \\
\hline 24 & $71 \mathrm{~F}$ & $80 \cdot 0$ & $26 \cdot 7$ & $\star$ & $\begin{array}{r}\text { Minut } \\
\text { pres }\end{array}$ & $\mathrm{J}$ vectors & Details indistinct & $\star$ & $\star$ \\
\hline 25 & $81 \mathrm{~F}$ & $78 \cdot 0$ & $25 \cdot 6$ & 100 & $8^{\circ}$ & $30^{\circ}$ & $\begin{array}{l}\text { Uniform for Ist } 45 \mathrm{msec} \text {; then } \\
\text { terminal slowing }\end{array}$ & $40^{\circ}$ & $20^{\circ}$ \\
\hline
\end{tabular}

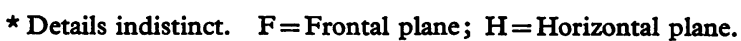

The correlation between the duration of the spatial $\mathrm{J}$ loop and the severity of the hypothermia is highly significant $(\mathrm{P}<0.0025)$.

Several factors made it difficult to obtain vectorcardiograms of good quality: a few of our patients had skeletal muscle tremor, intermittent and uncontrolled limb movements, Cheyne-Stokes respiration, and atrial fibrillation, all of which caused artefacts or interference with the terminal vectors of some of the tracings. In addition, a variety of disturbances of cardiac rhythm, including atrial fibrillation, ventricular ectopic beats, and atrioventricular dissociation, created difficulty in obtaining successive planar recordings. Moreover, simultaneous recording of the 3 planar projections of the vectorcardiogram was not possible with our apparatus. Minor discrepancies between the three planar vectorcardiograms could not therefore always be eliminated; whenever possible, however, the planar vectorcardio- grams were recorded during any periods of apnoea which were also free from tremor and limb movements. Time-marked and non-time-marked déroulé planar vectorcardiograms at maximum magnification on a timebased background were made when the Cambridge vectorcardiogram was used (Fig. 2) and the magnified records of the $J$ loops themselves were made whenever possible with both the Cambridge and the Sanborn apparatus. In some cases, large numbers of planar vectorcardiograms had to be recorded before a good quality trace was obtained for each of the 3 planes at both low and high magnification. Some unavoidable minor discrepancies had to be taken into account by the medical artist when making the three-dimensional reconstructions, which are therefore partly diagrammatic. 

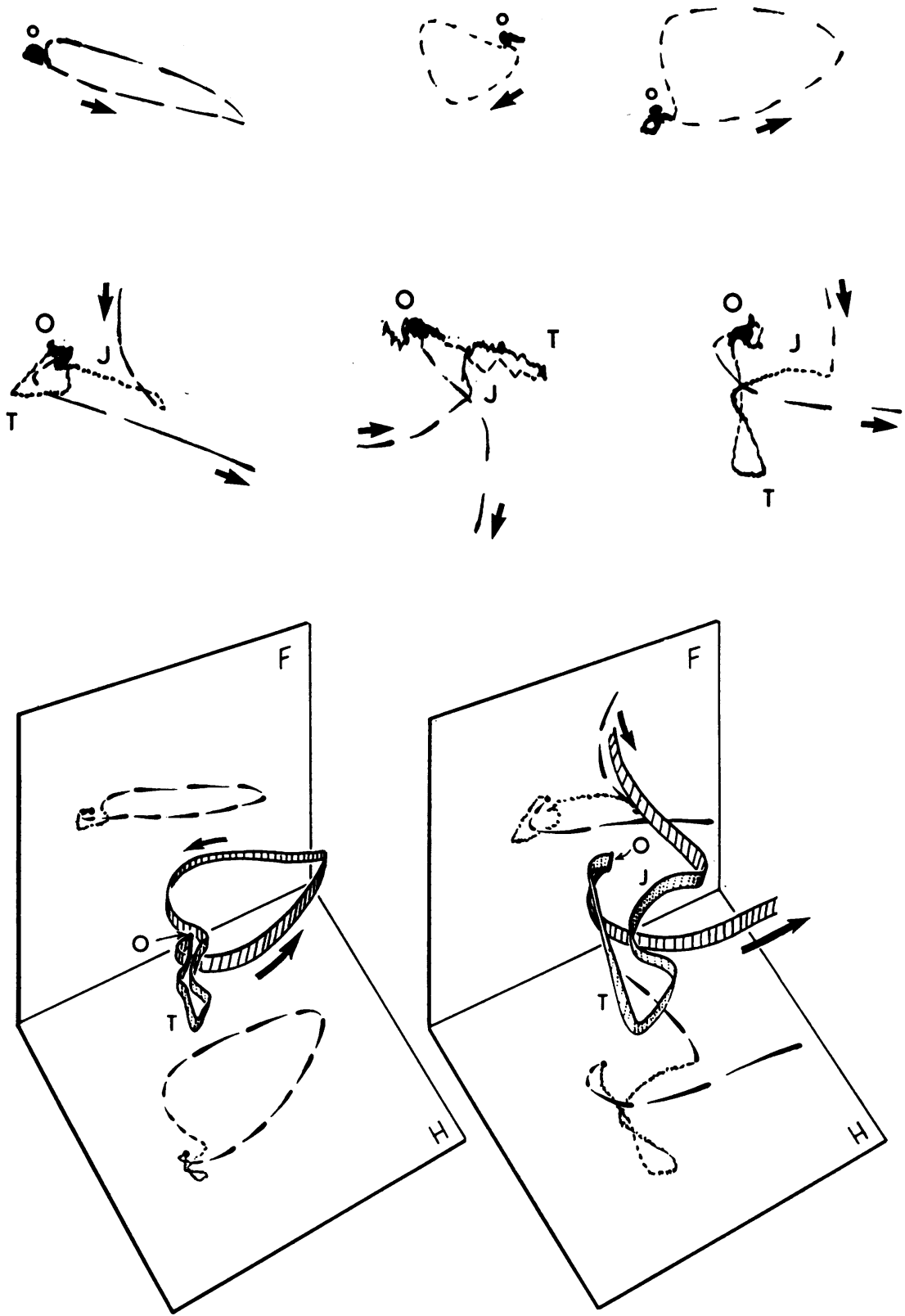

FIG. I a) The first electronically synthesized planar vectorcardiograms directly recorded from a patient with accidental hypothermia (Case $1,28 \cdot 3^{\circ} \mathrm{C}$ ). Frontal, right sagittal, and horizontal (left-to-right) planar projections are shown at two magnifications of the basic standardization ( $\times 2$ upper tracings, $\times 12$ lower tracings). A blanking pulse interrupts the loops every 5 msec. The direction of inscription of the loops is indicated by the arrows and their origin or null point by $O$. The last part of the centripetal limb of the QRS loop is suddenly deflected and then abruptly slowed, so that the QRS loop does not return to its point of origin ( $\mathcal{f}$ shift). There is progressive slowing of the rate of inscription of the $\mathcal{F}$ loop throughout its course. $b$ ) The spatial reconstructions (at two magnifications) derived from the frontal $(F)$ and horizontal $(H)$ planar projections are shown in Fig. Ia. 

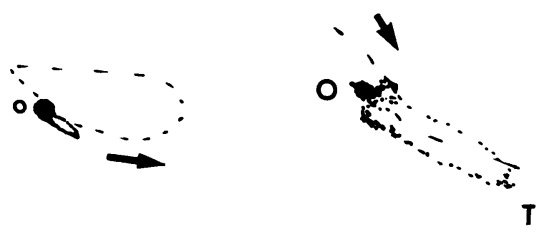

$T$

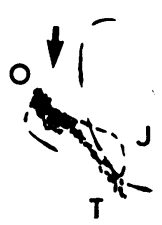

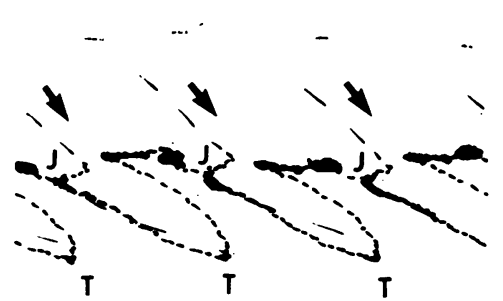

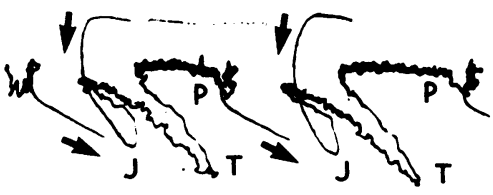

FIG. 2 Time-marked ( 5 msec blanking pulse) and non-time-marked planar vectorcardiograms directly recorded at various magnifications $(\times 12)$ of the basic standardization. Upper tracings: horizontal planar vectorcardiograms (from left to right, $\times 5, \times 12$, and $\times 12$ déroulé) recorded from Case $3\left(29 \cdot 0^{\circ} \mathrm{C}\right)$. Lower tracings: frontal planar vectorcardiograms (from left to right, $\times 2, \times 12$, and $\times 12$ déroulé) recorded from Case I after partial rewarming to $3 I^{\circ} I^{\circ} \mathrm{C}$. Only small parts of the $Q R S$ loops are seen in the $\times 12$ tracings. The arrows indicate the direction of inscription of the loops; $P$ loops are present in addition to the $\mathcal{F}$ loops and $T$ loops in the lower tracing.

\section{Results}

With one exception (Case II, Table), all the vectorcardiograms recorded from hypothermic patients showed recognizable displacements of the $J$ point ('ST vectors'), and characteristic open J loops as have been described for indirectly derived spatial vectorcardiograms (Emslie-Smith, 1958b).

The present study, however, demonstrated clearly that though the speed of inscription of the vector loop did slow abruptly at the junction of the QRS and J loops, as the earlier study, based on indirect derivation, had suggested (Emslie-Smith, 1958b), the rate of inscription of the J loop itself did not always slow progressively throughout its course. In $2 \mathrm{I}$ of the patients the technical quality of the records was good enough to allow a clear assessment of the rate of inscription of the J loop. In only 4 cases did the rate of inscription of the J loop slow progressively throughout its course (Fig. I); in another 6 cases progressive slowing only occurred towards the end to the J loop (Fig. 3a), whereas in the remaining II cases the $J$ loops were inscribed throughout at a uniform rate which was slightly faster than that of the subsequent $T$ wave (Fig. $3 b$ and Table). In general, the voltage of the $J$ vectors decreased progressively until the start of the $T$ loop was reached. The duration of the $J$ loop ranged from 40 to $160 \mathrm{msec}$ in this series, there being a highly significant correlation $(\mathrm{P}<0.0025)$ between this and the severity of the hypothermia. In the first patient (Table), for example, the duration of the $J$ loop fell by $20 \mathrm{msec}$ after rewarming by $2 \cdot 8^{\circ} \mathrm{C}$. The previous finding that hypothermia greatly increased the QRS-T spatial angle (Emslie-Smith, 1958b) was well confirmed by the findings in Case 20 (Table and Fig. 4).

The vectorcardiogram of one patient (Case II, Table) did not show any recognizable displacement of the J point (Fig. 5), despite a very low body temperature $\left(25.6^{\circ} \mathrm{C}\right)$. The hypothermia in this case was a complication of severe glutethimide ('doriden') poisoning and had a fatal outcome. The patient had also previously sustained an anteroseptal cardiac infarction which was confirmed at necropsy. The significance of these observations is not clear.

The main spatial QRS loop, though often larger than its euthermic counterpart (Fig. 4), is essentially normal in patients with accidental hypothermia who have not previously sustained myocardial damage. Below $31.9^{\circ} \mathrm{C}$, consistent changes appeared in the terminal crochet of the spatial QRS loop, in the junction (J) of the QRS and T loops, and in the T loop. The last part of the centripetal limb of the QRS loop is suddenly deflected and then abruptly slowed, so that the QRS loop does not return to its 

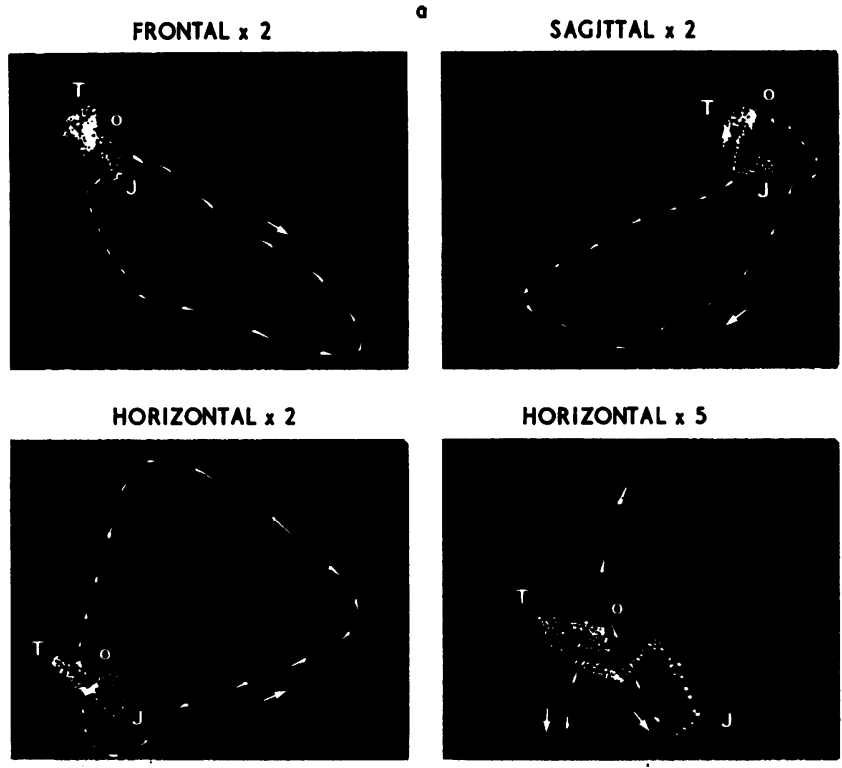

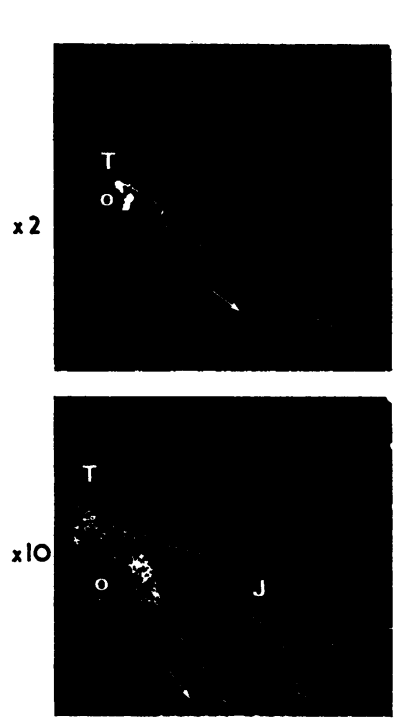

FRONTAL
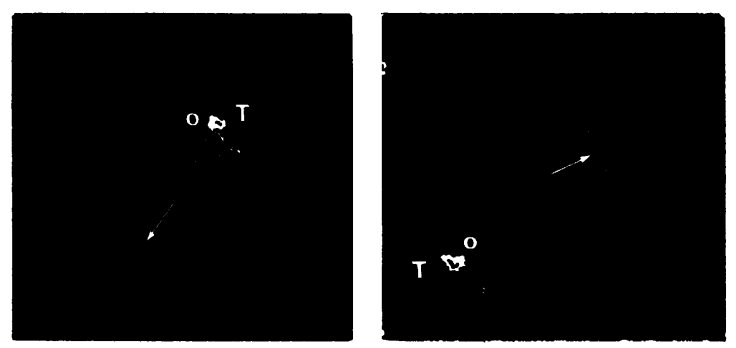

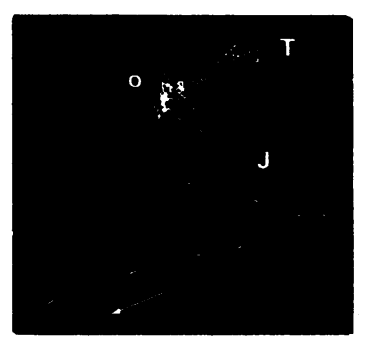

SAGITTAL

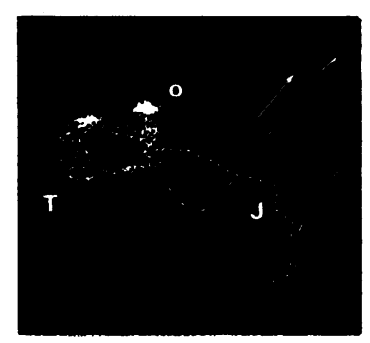

HORIZONTAL

FIG. 3 a) Planar vectorcardiograms recorded from Case 20 at $22 \cdot 8^{\circ} \mathrm{C}$. Upper tracings: frontal and right sagittal recorded at $\times 2$, the basic sensitivity. Lower tracings: horizontal $\times 2$ and $\times$ 5. The $\mathcal{F}$ loop $(\mathfrak{F})$ is within the main $Q R S$ loop and its rate of inscription slows only towards its end and before it joins the $T$ loop $(T)$. The point of origin of the $Q R S$ loop is represented by $O$. b) Frontal, right sagittal, and horizontal planar vectorcardiograms (upper tracings $\times 2$; lower tracings $\times 10$ ) recorded from Case 22 at $27 \cdot 8^{\circ} \mathrm{C}$. The arrows indicate the direction of inscription of the main QRS loops and $O$ their origin. The rate of inscription of the $\mathcal{F}$ loop $(\mathcal{F})$ is uniform throughout and faster than that of the subsequent $T$ loop $(T)$. This patient had previously sustained an anterior cardiac infarction with partial involvement of the interventricular septum. 

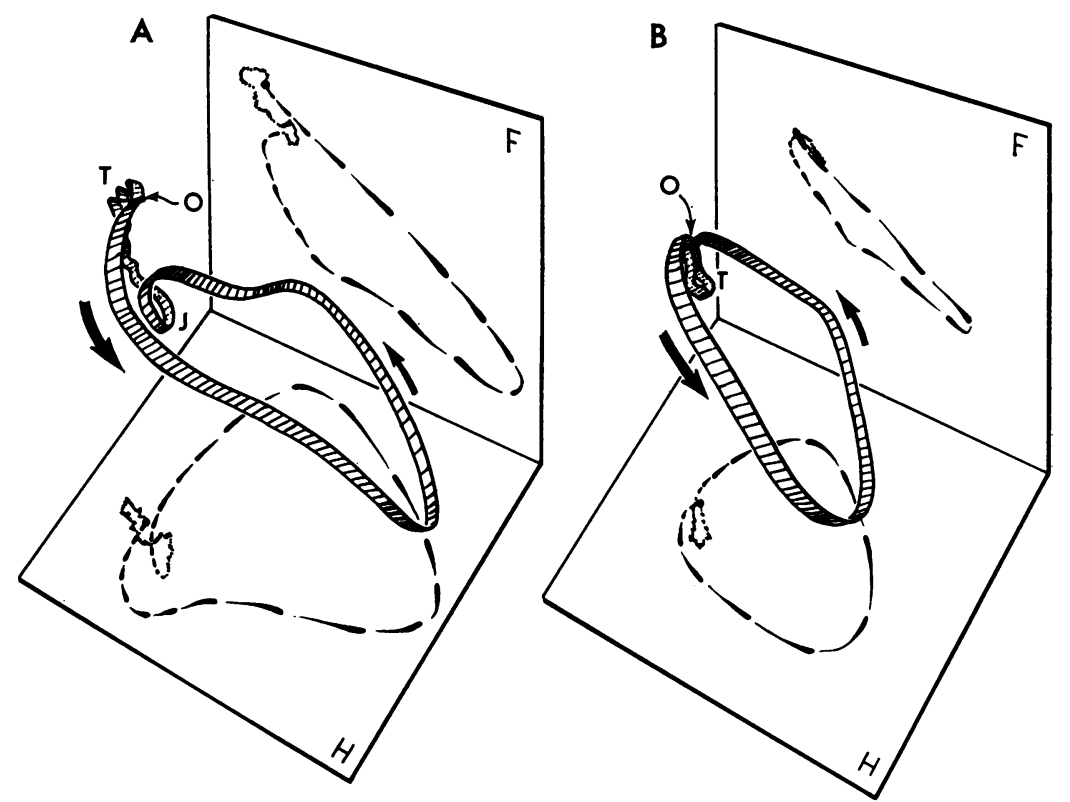

FIG. 4 The spatial vectorcardiogram reconstructed from the frontal $(F)$ and horizontal $(H)$ planar projections recorded from Case 20 at two body temperatures: (A) at $22 \cdot 8^{\circ} \mathrm{C}$, and (B) at normal body temperature $\left(36.9^{\circ} \mathrm{C}\right) 3$ months after recovery from his hypothermic episode. The standardization was the same for each recording. The origin of each loop is indicated by $O$ and the direction of inscription by the arrows. The planar projections are time marked using a $5 \mathrm{msec}$ blanking pulse. In addition to the $Q R S$ loop during hypothermia being considerably larger than its euthermic counterpart, there is also an additional, smaller $\mathcal{F}$ loop within it. The spatial $Q R S-T$ angle is greatly increased in the loop recorded during hypothermia, the axes of the two loops being almost $180^{\circ}$ apart.

point of origin ( $\mathrm{J}$ shift) but continues to form an extra, conspicuous open loop, which may be inscribed either clockwise or anticlockwise in both the frontal and horizontal planes, and is directed usually downward, forward, and to the left, between the QRS and T loops (Fig. I and 4). The rate of inscription of the J loop may be uniformly slow throughout or it may slow progressively either throughout its course or only in its last part (Table and Fig. I and $3 a$ and $b$ ). The J loop in turn continues into a more or less $U$-shaped $T$ loop which lies in a direction different from that seen at normal temperature, and usually outside the main QRS loops, even to the extent of the main axes of the two loops, being almost $180^{\circ}$ apart (Fig. I and 4).

\section{Discussion}

In scalar electrocardiograms from hypothermic man and animals a $\mathrm{J}$ deflection is almost always seen at body temperatures of $31.0^{\circ} \mathrm{C}$ or lower (EmslieSmith, 1956), and in the spatial vectorcardiogram it is represented by the $\mathrm{J}$ loop (Emslie-Smith, I958b). The J deflection in scalar leads is often an obvious and discrete part of the QRS-T complex, directed either upward (Fig. 6, leads $V_{3}$ to V6, and Fig. 7, A and B) or downward (Fig. 6, leads VR and III, and Fig. 7, A and B). Frequently, however, it takes the form of relatively inconspicuous widenings of the base of the QRS complex with or without 'ledging' (Fig. 6, leads I and VL, and Fig. 7A). These scalar effects are often unrecognized, and, indeed, in some leads the QRS-T complex may even appear normal (Fig. 6, lead VI). The reason for these variable scalar configurations can only be appreciated by an understanding of the spatial relations between the spatial J loop of the vectorcardiogram and the positions of the scalar electrodes. This is demonstrated in Fig. 6.

These scalar $\mathrm{J}$ waves have also been recorded from oesophageal and direct epicardial leads in experimental animals (Emslie-Smith, 1956, 1957; Read et al., 196I) (Fig. 7B). 


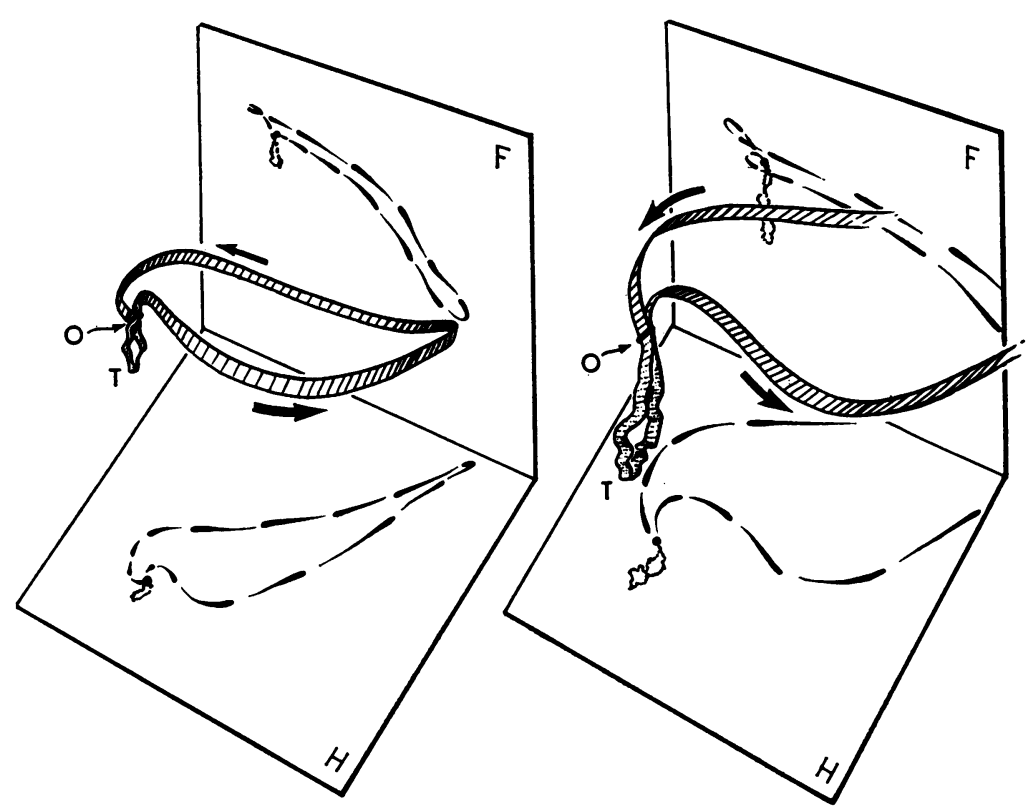

FIG. 5 Spatial vectorcardiograms reconstructed from two magnifications of the frontal $(F)$ and horizontal $(H)$ planar vectorcardiograms ( 5 msec blanking pulse) recorded from Case II $\left(25.6^{\circ} \mathrm{C}\right)$. The patient, a few years previously, had sustained an anteroseptal cardiac infarction and his hypothermia was due to severe self-poisoning with glutethimide ('doriden'). The spatial $Q R S$ loops, the direction of inscription of which is indicated by the arrows, confirm the scalar electrocardiographic and planar vectorcardiogram findings of no recognizable $\mathcal{F}$ shift, despite the very low body temperature. The main $Q R S$ loop returns to its point of origin $(O)$ before the $T$ loop is inscribed. The spatial $T$ loop itself has an abnormal axis, which could be attributed both to the previous cardiac infarction and to the hypothermia.

There has been much speculation about the genesis of these unique $\mathrm{J}$ loops and $\mathrm{J}$ deflections, but it is a fact that hypothermia causes a characteristic dip in the early repolarization phase of the transmembrane action potential in cells from human atrium (Sleator and de Gubareff, 1964), cat papillary muscle (Trautwein and Dudel, 1954), and dog ventricle (West, Frederickson, and Amory, 1959; Toyoshima et al., 1965) (Fig. 7C). West et al. (1959) have suggested that in the ventricular myocardium of the dog, this phase of the membrane action potential may be largely determined by transmembrane potassium ion flux; Trautwein (1969) has suggested that in Purkinje fibres it is determined by transmembrane chloride ion flux. We have already demonstrated in our patients with accidental hypothermia, including many in the present series, very high levels of activity in the serum of muscle enzymes, particularly of adenosine-triphosphate-creatine phosphotransferase (cre- atine kinase, E.C. 1 .7.3.2.) and $\alpha$-hydroxybutyrate dehydrogenase (Maclean, Griffiths, and EmslieSmith, 1968; Maclean, Murison, and Griffiths, 1974). The myocardium is a rich source of these enzymes so that in part, at least, these high serum levels may reflect alterations in the permeability of the myocardial cell membranes, thus providing support for the idea that the spatial $J$ loop and scalar $\mathrm{J}$ deflection are the result of an altered ion flux across the myocardial sarcolemma in hypothermia.

We thank Professor Sir Ian Hill and Professor K. G. Lowe for their interest and support and the other physicians of the Dundee teaching hospitals for allowing us to study patients in their care. We are also indebted to Miss Mary Benstead for drawing the spatial reconstructions and the illustrations of the variety of forms of the J deflection. We are grateful to the British Heart Foundation and the Scottish Hospitals Endowment Research Trust for financial assistance. 


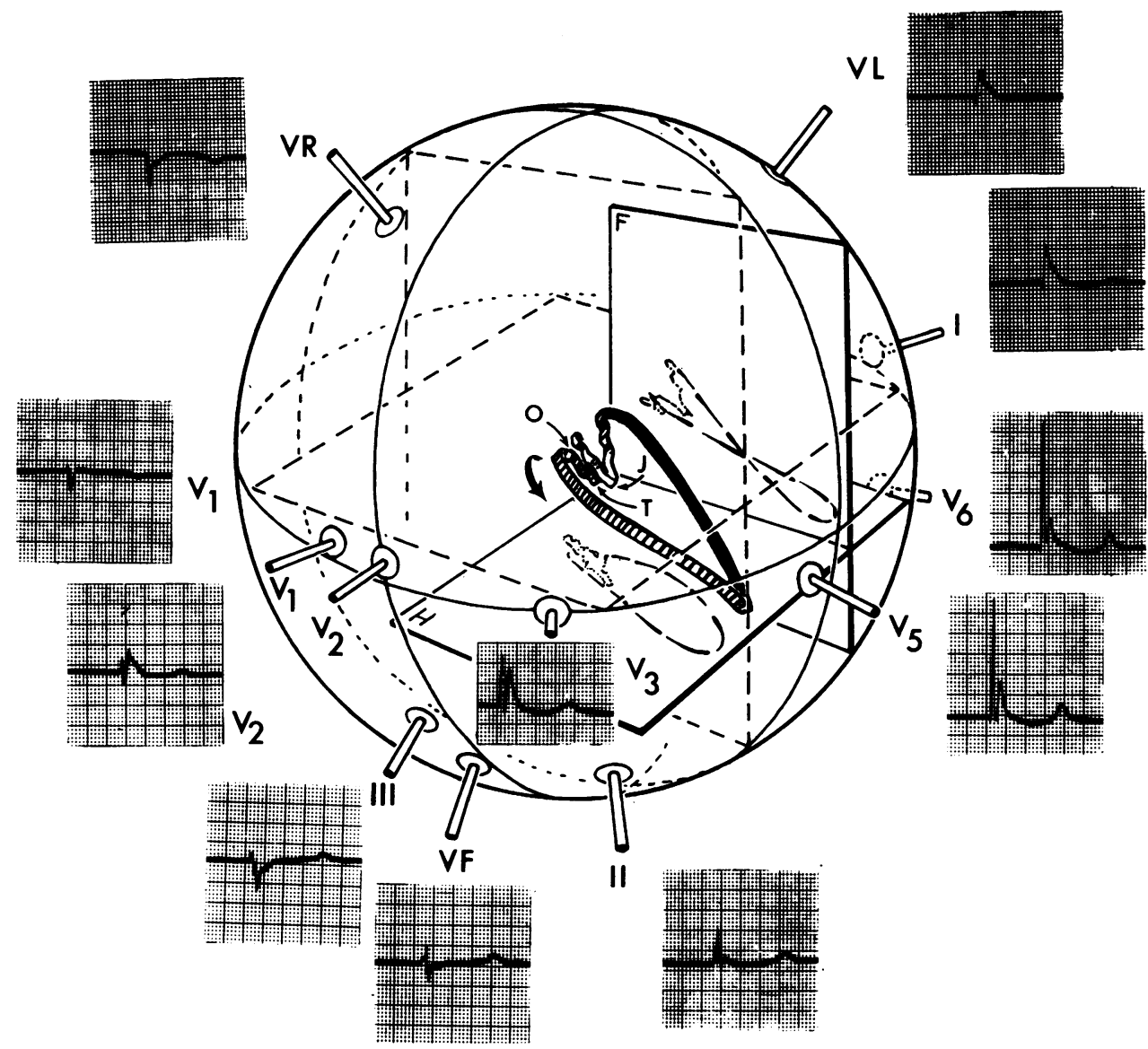

FIG. 6 Diagram to show the relation between the spatial vectorcardiogram, the frontal $(F)$ and horizontal $(H)$ planar vectorcardiograms, and the scalar electrocardiogram of Case $25\left(25.6^{\circ} \mathrm{C}\right)$. The spatial arrangement of the scalar lead axes is in accordance with the Burger scalene triangle for the limb leads and that suggested by Lamb (1965) for the chest leads, modified to allow for the fact that in clinical practice the praecordial electrode sites do not all lie in the same plane. The form and sign of the $\mathcal{F}$ deflection in the records from different scalar leads vary and are determined by the relation between the position in space and the duration of the $\mathcal{F}$ vectors and the plane through the origin $(O)$ of the spatial $Q R S$ loop which is perpendicular (or normal) to the axis of any lead.

\section{References}

Cameron, A. J. V., Lawrie, T. D. V., and Wright, J. H. (1959). A twin oscilloscopic vectorcardiograph. British Heart fournal, 2r, 505.

Emslie-Smith, D. (1956). Changes in the electrocardiogram during preoperative hypothermia in man. Australasian Annals of Medicine, 5, 62.

Emslie-Smith, D. (1957). The electrical activity of the heart in hypothermia. M.D. Thesis, University of Aberdeen.

Emslie-Smith, D. (1958a). Accidental hypothermia. A common condition with a pathognomonic electrocardiogram. Lancet, 2, 492.
Emslie-Smith, D. (1958b). The spatial vectorcardiogram in hypothermia. British Heart fournal, 20, 175.

Emslie-Smith, D., Sladden, G. E., and Stirling, G. R. (1959). The significance of changes in the electrocardiogram in hypothermia. British Heart fournal, $21,343$.

Fleming, P. R., and Muir, F. H. (1957). Electrocardiographic changes in induced hypothermia in man. British Heart fournal, 19, 59.

Frank, E. (1956). An accurate, clinically practical system for spatial vectorcardiography. Circulation, 13, 737.

Gillmann, H. (1958). Vektorielle Untersuchungen über die durch künstliche Hypothermie ausgelösten EKG-Veränderungen. Cardiologia, 33, 2 I. 


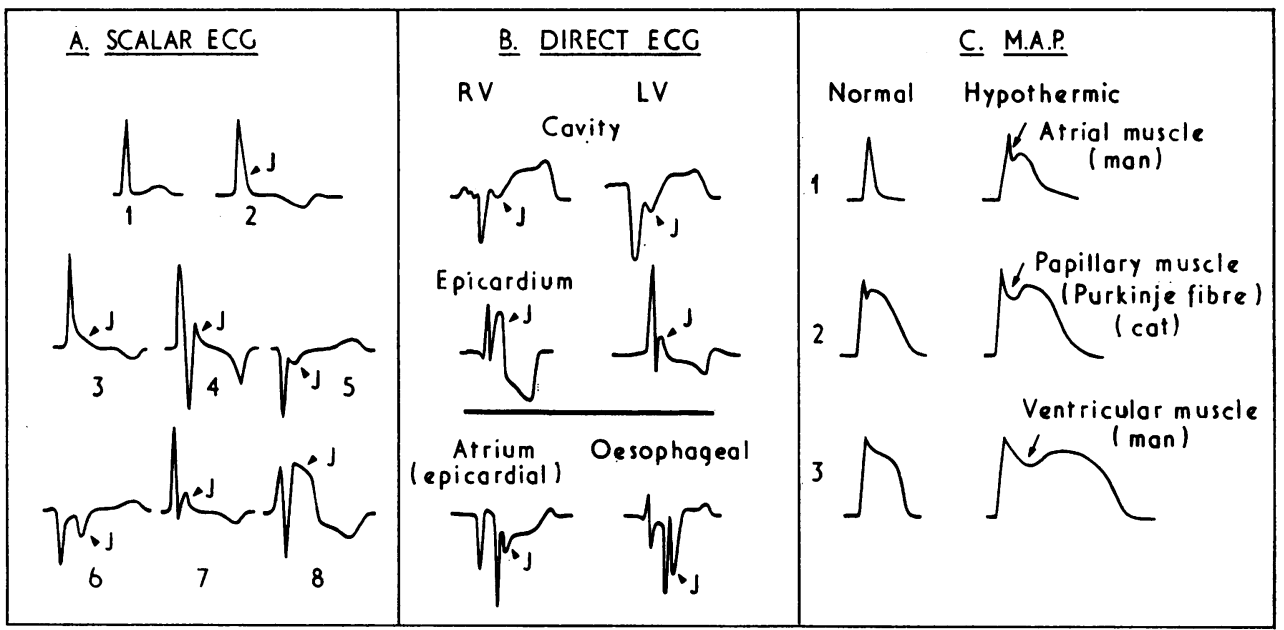

FIG. 7 Diagram to show the various forms of the 7 deflection of hypothermia in the scalar (A), and the direct (B), electrocardiogram. The effects of hypothermia on the membrane action potential (M.A.P.) are shown in (C). A) Scalar records from patients: I) Normal; 2) widening of the base of the $Q R S$ complex ( $R$ wave); 3) and 4) 'ledging'; 5) and 6) inverted f deflections in $V R$ and right chest leads 7) and 8); upright $\mathcal{f}$ deflections in left chest leads. B) Direct scalar electrocardiograms recorded from dogs: right ventricular $(R V)$, and left ventricular $(L V)$, cavity and epicardial electrograms. Atrial (epicardial) and oesophageal electrocardiograms (Emslie-Smith, 1957). C) Characteristic changes in the membrane action potential on cooling, based on transmembrane recordings published by the authors named in parenthesis: 1) human atrial muscle (Sleator and de Gubareff, 1964); 2) feline papillary muscle (or Purkinje fibre) (Trautwein and Dudel, 1954); 3) human ventricular muscle (West et al., 1959): hypothermia causes a characteristic dip in the early repolarization phase (arrowed).

Grosse-Brockhoff, F., and Schoedel, W. (1943). Das Bild der akuten Unterkühlung im Tierexperiment. NaunynSchmiedebergs Archiv für Experimentelle Pathologie und Pharmakologie, 201, 417.

Lamb, L. E. (1965). Electrocardiography and Vectorcardiography, p. 72. Saunders, Philadelphia.

Maclean, D., Griffiths, P. D., and Emslie-Smith, D. (1968). Serum-enzymes in relation to electrocardiographic changes in accidental hypothermia. Lancet, 2, 1266.

Maclean, D., Lowe, K. G., and Emslie-Smith, D. (1970). Effect of posture on the spatial vectorcardiogram of man. Cardiovascular Research, 4, 490.

Maclean, D., Murison, J., and Griffiths, P. D. (1974). Serum enzyme activities in accidental hypothermia and hypothermic myxoedema. Clinica Chimica Acta, 52, 197.

Read, A. E., Emslie-Smith, D., Gough, K. R., and Holmes, R. (196r). Pancreatitis and accidental hypothermia. Lancet, 2, I2I9.

Rees, J. R. (1958). Accidental hypothermia. Lancet, I, 556.

Royal College of Physicians of London (1966). Report of the Committee on Accidental Hypothermia. Royal College of Physicians, London.

Sleator, W., and de Gubareff, T. (1964). Transmembrane action potentials and contractions of human atrial muscle. American fournal of Physiology, 206, 1000.
Tomaszewski, W. (1938). Changements électrocardiographiques observés chez un homme mort de froid. Archives des Maladies du Coeur et des Vaisseaux, 31, 525.

Toyoshima, H., Prinzmetal, M., Horiba, M., Kobayashi, T., Mizuno, Y., Nakayama, R., and Yamada, K. (1965). The nature of normal and abnormal electrocardiograms. VIII: Relation of ST segment and $T$ wave changes to intracellular potentials. Archives of Internal Medicine, 115, 4.

Trautwein, W. (1969). Generation of the cardiac action potential. In Electrical Activity of the Heart, p. 9. Ed. by G. W. Manning and S. P. Ahuja. Charles C. Thomas, Springfield, Illinois.

Trautwein, W., and Dudel, J. (1954). Aktionspotential und Mechanogramm des Katzenpapillarmuskels als Funktion der Temperatur. Pflügers Archiv für die gesamte Physiologie des Menschen und der Tiere, 260, 104.

West, T. C., Frederickson, E. L., and Amory, D. W. (1959). Single fiber recording of the ventricular response to induced hypothermia in the anesthetized dog. Correlation with multicellular parameters. Circulation Research, 7, 880.

Requests for reprints to Dr. D. Maclean, Department of Medicine, Ninewells Hospital, Dundee DDr 9SY. 